\title{
Effect of Natural Gastrointestinal Parasitic Infection on Carcass Yield and Characteristics of Sudan Desert Sheep

\author{
Nazik Z Eisa ${ }^{{ }^{*}}$, Salih A Babiker ${ }^{2}$ and Hamid S Abdalla ${ }^{3}$
}

\author{
${ }^{1}$ Department of Animal Production, Faculty of Agriculture, University of Gezira, Wad Medani, Sudan \\ ${ }^{2}$ Department of Meat Production, Faculty of Animal Production, University of Khartoum, Khartoum, Sudan \\ ${ }^{3}$ Department of Parasitology, Faculty of Veterinary Sciences, University of Khartoum, Khartoum, Sudan
}

Received: 13 April, 2017; Accepted: 16 May, 2017; Published: 29 May, 2017

*Corresponding author: Nazik Z Eisa, Department of Animal Production, Faculty of Agriculture, University of Gezira, Wad Medani, Sudan. E-mail: eisanazik@uofg.edu.sd

\begin{abstract}
This study was conducted to detect the effect of natural gastrointestinal parasitic infection along with age and level of energy on the carcass yield and characteristics of Sudan Desert sheep. Forty-eight lambs were divided into eight groups of 6 animals each and fattened for 60 days. A total of twenty four animals ( 3 from each group) were selected for slaughter at the end of the fattening process. The study revealed significant differences in slaughter weights $(\mathrm{P}<$ $0.05)$, carcass weights $(P<0.05)$ and carcass characteristics. Both hot and cold empty body weights and dressing percentages were significantly $(\mathrm{P}<0.01)$ affected by internal parasitic infection and dietary energy level. Wholesale cuts yields and loin composition were not significantly affected by infection except for muscle percentage (P $<0.05$ ).
\end{abstract}

Keywords: Sheep; Carcass; Natural infection; Gastrointestinal parasitic; Economics

\section{Introduction}

According to the Ministry of Livestock, Fisheries and Range lands of the Sudan 2015 the livestock population of Sudan, amount to 114 million head of which the sheep comprise about 40 million head. Desert sheep comprise about $80 \%$ of the slaughtered sheep in Sudan which greatly contributes in supplying both local markets and exportation [1]. Gastrointestinal nematodes represent a major production problem for ruminant which might be due to a combination of several factors such as climate, level of dietary energy, age, and sheep general health $[2,3]$. Helminthiasis cause loss of production through mortality, weight loss and reduced meat production leading to serious industrial and economic losses [4]. Sheep affected by worms show reduced appetite for pasture and reduction in feed intake of up to $10 \%$ by infections caused by H. contortus and Brown Stomach worms [5]. Helminth parasites limit sheep production, due to the direct effects of their blood feeding behavior [6]. Change in body weight is probably the most widely used criterion for judging the effect of gastrointestinal parasitism on the host. However, such changes do not take account of alterations in body composition which may be of considerable importance in determining carcass quality. Obviously carcass and meat quality of lambs are greatly affected by feeding systems mainly with regard to carcass conformation and fatness degree as confirmed by [7]. Upon studying sheep gastrointestinal parasitism, had demonstrated severe small intestine lesions, such as villous atrophy and epithelial erosion, which impaired the digestion and absorption of nutrients, causing a significant loss in performance [8]. This might lead to partial or complete condemnations of the carcasses at the slaughterhouses [9]. In Sudan, a different kind of internal parasites has been recovered from sheep according to Atta El Mannan [10]. Up till now the study of the link between natural parasitic infection and sheep productivity has never been covered. This study aimed to evaluate the effect of natural gastrointestinal infection on carcass yield and characteristics of Sudan Desert sheep.

\section{Materials and Methods}

\section{Animals}

Forty-eight naturally infected Sudan Desert sheep (Hamary type) with an average initial live weight of $24.13 \mathrm{~kg} \pm \mathrm{kg} 1.22$ were used for this study. The study was conducted at the Department of Animal Nutrition, Faculty of Animal Production, University of Khartoum, Khartoum North, Sudan. After being screened for internal and external parasites, all animals were treated with Cypermethrin (ectothrin) against external parasites while half of them were treated for internal parasites as the control and the rest were left as naturally infected (Table 1). Antibiotic injections (Oxytosin-10\%) were given for protection against respiratory diseases and coccidiobans against coccidiosis. Half of the control group (12 out of 24 ) were less than one year old (milk teeth) and the other half were two years old. Half of the group was supplied with high energy diet while the rest were given low energy diet. Same applied for the naturally infected group ending up with 8 
groups (6 animals each) with equal average weight. Each two animals were kept in a pen provided with water, feed and salt lick cubes.

\begin{tabular}{|c|c|c|}
\hline Ingredients & $\begin{array}{c}\text { High energy diet } \\
\text { (\%) }\end{array}$ & $\begin{array}{c}\text { Low energy diet } \\
(\%)\end{array}$ \\
\hline Sorghum grains & 40.00 & 4.00 \\
\hline Wheat bran & 15.00 & 5.00 \\
\hline Groundnut cake & 11.00 & 6.00 \\
\hline Molasses & 14.00 & 30.00 \\
\hline Groundnut hulls & 17.80 & 51.40 \\
\hline Urea & 0.20 & 2.40 \\
\hline Limestone & 1.00 & 1.00 \\
\hline Common salt & 1.00 & 1.00 \\
\hline 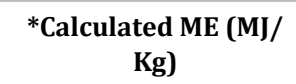 & 12.24 & 10.35 \\
\hline Calculated CP (\%) & 16.11 & 16.11 \\
\hline
\end{tabular}

\section{Experimental design}

The design depends on three parameters which were health, age and dietary energy level. At the end of the adaptation period individual initial weight was taken after an overnight fasting except for water. Animals were randomly divided into two groups of twenty-four animals each. One group was treated for internal parasites while the other group was left naturally infected. Each group was further subdivided into four subgroups of six animals each. Further subgroubing was done through keeping each two animal in a pen provided with water and feed facilities. Each group was divided in to two sub-groups according to age, old (2 years) and young (one year), dietary energy (high and low), and health (treated and naturally infected). The design ended up with 8 groups which were, Old Treated High Energy (OTHE), Old Infected High Energy (OIHE), Old Treated Low Energy (OTLE), Old Infected Low Energy (OILE), Young Treated High Energy (YTHE), Young Infected High Energy (YIHE), Young Treated Low Energy (YTLE) and Young Infected Low Energy (YILE).

\section{Determination of parasites}

Upon arrival animals were screened for parasites. Manual search for ticks was done and rectal fecal samples were taken gently for internal parasites detection. This was done weekly throughout the adaptation experimental periods

\section{Determination of parasites}

At the start of the experiment all experimental animals were treated for external parasites by using Ectothrin dipping solution. Internal parasites Anthelmintics were applied in the very beginning to treat the group of animals need to be treated, then for the rest of the experiment for the treated group as prevention. Anthelmintics given were Albendazole drug for internal parasites as a broad spectrum anthelmintic. Ivermectin is provided for both internal and external parasites. They were given in turns twice a month as a protection. Coccidiobans were given for all experimental animals for treatment and control of coccidian infection throughout the experimental time. Oxytetracyclin and Gentamycine were used against respiratory tract infections.

\section{Feed and Feeding}

Two iso-nitrogenous diets of high and low energy were formulated. The ingredients of the experimental diets are given in (Table 1). Ingredients proportions of the experimental diets were calculated according to [11].

Feed was offered ad lib in the early morning (8.00 am). Feed refusals were collected and weighed every day in the morning before feeding throughout the data collection period. Samples of feed offered and refused were taken weekly for analyzing DM, then pooled to monthly samples for further analysis. Feed intake of each group was recorded daily and calculated as the difference between the weight of the quantity offered and refusal on the next morning. The average dry matter of the experimental diet and the refusal were obtained to calculate dry matter intake.

\section{Slaughter procedure and samples preparation}

At the end of the experiment a total of twenty four animals (three from each treatment) were randomly selected for slaughter. They represented all different sub groups. Slaughter weight for each animal was taken just before slaughtering after an overnight fast except for water. The slaughtering process was performed according to the international Muslim practice, where the jugular vein and carotid artery were severed as well as the oesophagus and trachea, using a sharp knife without stunning.

\section{Carcass data}

The hot carcass weight was obtained after removal of external and internal non carcass components. After chilling of the whole carcass at $4^{\circ} \mathrm{C}$ for 24 hours, the cold carcass weight was taken. The carcass was then split along the vertebral column into approximately two equal halves. The left side of the carcass was prepared for cutting. First the pelvic fat, the kidney and the kidney fat were removed and weighed separately. The dressing out percentage was calculated on the basis of hot and cold carcass weights. Samples from longissimus dorsi muscle were taken for chemical analysis and meat quality parameters determination.

\section{Carcass wholesale cuts yield}

The left side of each carcass was separated into whole sale cuts according to [12]. The cuts were: Neck, Single short quarter, Leg and Chump, Loin, Best End of Neck, Brest and Tail. Each wholesale cut was weighed and expressed as percentage of carcass side weight.

\section{Dissection of loin cut}

Loin cut was placed on a moist towel to prevent evaporation. Forceps and plates were used to remove subcutaneous layer as well as other tissues such as blood vessels, lymph ducts and nerves. Muscles were then separated from bones. Intermuscular fat and connective tissues were also dissected out. The separated 
tissues including muscles, bones, fat and trimmings (connective tissues, fascia, blood vessels, lymph ducts and nerves) were placed on trays covered with wet towels to avoid desiccation. All removed parts were weighed using (OHAUS) balance of 20 $\mathrm{kg}$ maximum capacity load to the nearest ( $\mathrm{gm}$ ) and expressed as percentage of joint weight.

\section{Economic calculation of carcasses of experimental lambs}

Calculation of prices on base of cold carcass weight was done regardless of purchase prices.

\section{Results}

\section{Prevalence of parasites in experimental lambs}

Table 2 shows the prevalence of both internal and external parasites in the experimental lambs. All animals were found to be infected with either Internal Parasites (IP), External Parasites (EP) or both of them. Those infected with internal parasites were (96\%) while those infected with external parasites were (52\%).

Table 3 shows the first week screening for internal parasites. All lambs were found to be infected with internal and or external parasites. Ninety six percentages of lambs were found to be infected with internal parasites only (Trichostrongyles, Monieza and coccidia). Of the internal parasites Trichostrongyles was the most dominant parasite (80\%), followed by Monieza (40\%), Coccidia (26\%), mixedinfection comprised of Trichostrongyles and Monieza (33\%), Trichostrongyles and coccidia (31\%), Monieza and coccidia (17\%) and Trichostrongyles, Monieza and coccidia is $(15 \%)$
Table 2: Natural infection of experimental animals (internal and external parasites)

\begin{tabular}{|c|c|c|c|}
\hline Trait & $\begin{array}{c}\text { Infected } \\
\text { (IP\&EP) }\end{array}$ & $\begin{array}{c}\text { Infected } \\
\text { (IP) }\end{array}$ & $\begin{array}{c}\text { Ticks } \\
\text { (EP) }\end{array}$ \\
\hline $\begin{array}{c}\text { No. of } \\
\text { lambs(48) }\end{array}$ & 48 & 46 & 25 \\
\hline No. of inf. lambs & 100 & 96 & 52 \\
\hline \%of inf. lambs & & \\
\hline \multicolumn{2}{|l|}{$\begin{array}{l}\text { In this table and the following ones: } \\
\text { IP: Internal Parasites; EP: External Parasites }\end{array}$} \\
\hline
\end{tabular}

Table 3: Prevalence of fecal ova at first week screening for internal parasites

\begin{tabular}{|c|c|c|}
\hline Trait & No. of IL & \% of IL \\
\hline Number of animals =48 & & \\
\hline IP: Internal parasites & 46 & 96 \\
\hline Trichostrongylus & 38 & 82.60 \\
\hline Monezia & 19 & 41.30 \\
\hline Coccidia & 21 & 45.65 \\
\hline Trichostrongylus+ Monezia & 16 & 34.65 \\
\hline Trichostrongylus+ Coccidia & 15 & 32.61 \\
\hline Monezia + Coccidia & 8 & 17.39 \\
\hline Trichostrongylus+ Monezia + Coccidia & 7 & 15.22 \\
\hline IL: Infected Lambs & & \\
\hline
\end{tabular}

Table 4: Effects of internal parasites in relation to age and energy level on carcass characteristics and sales

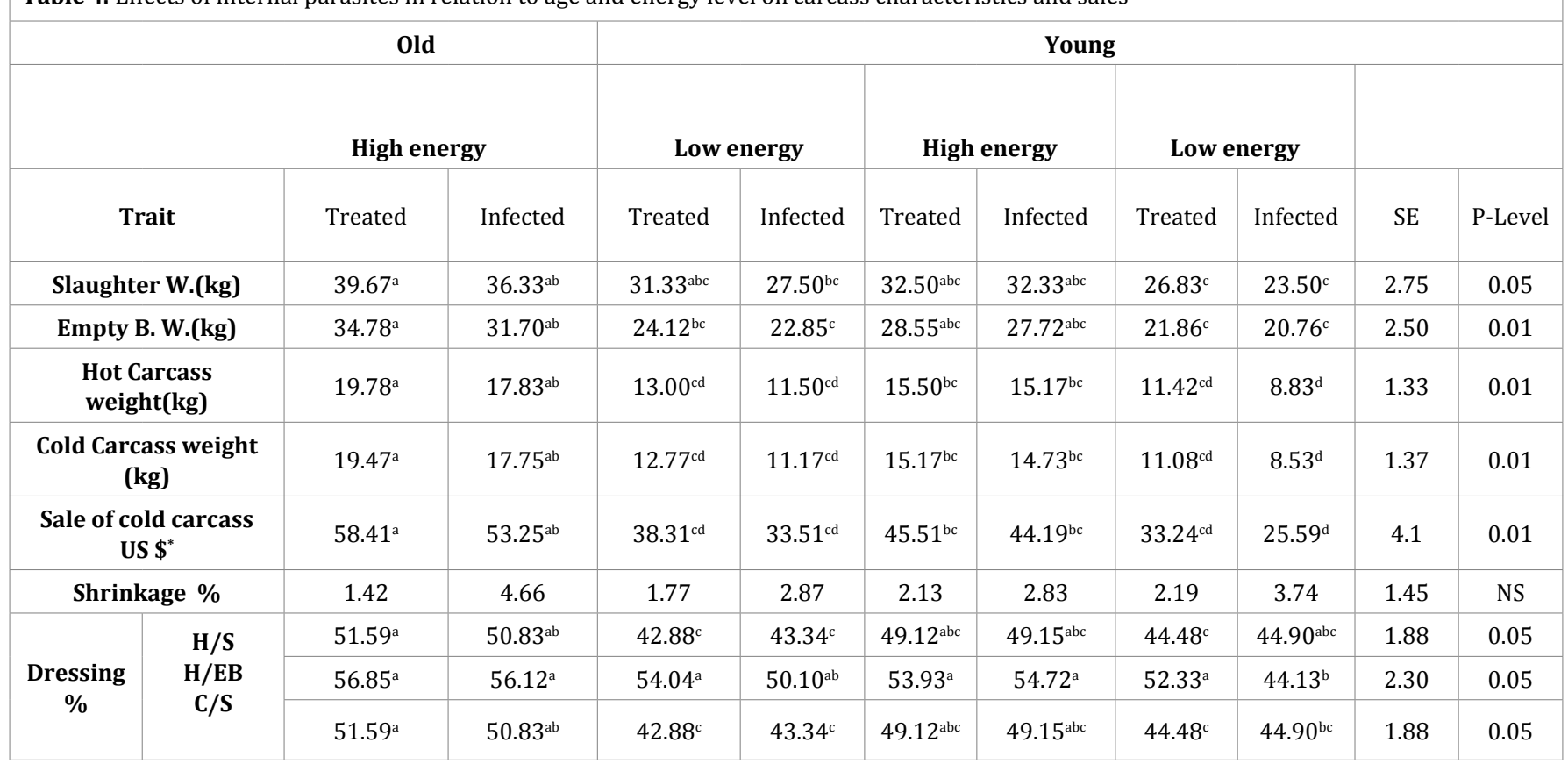




\section{Carcass Characteristics}

Table 4 gives data related to carcass characteristics of desert sheep fed high or low energy diet and treated for internal parasites or left naturally infected. The best slaughter weight was that of old lambs treated for internal parasites and given high energy diet ( $39.67 \mathrm{~kg}$ ). It was $16.17 \mathrm{~kg}$ higher than that of young infected group given low energy diet and $12.17 \mathrm{~kg}$ more than that of old lambs left naturally infected and given low energy, too. Slaughter weights of all treated groups whether given high or low energy diets were heavier than their counterpart infected groups. Slaughter weights of all young lamb groups were less than those of old lamb groups e.g. that of young lambs treated for internal parasites and given high energy diet was $32.50 \mathrm{~kg}$ which was about $7 \mathrm{~kg}$ less than old lambs given the same energy diet and treated for internal parasites. The least carcass weight was that of infected young lambs given low energy diet. Empty body weight followed the same pattern as slaughter weight. The highest empty body weight was achieved by the group of old lambs that was treated for internal parasites and fed high energy diet (34.78 $\mathrm{kg}$ ) which was $14.02 \mathrm{~kg}$ more than the least empty body weight which was performed by the group of infected young lambs given low energy diet. Hot carcass weight of old lambs treated for internal parasites and given high energy diet was $19.78 \mathrm{~kg}$ which was only $1.95 \mathrm{~kg}$ higher than that of old lambs left naturally infected, but it was $10.95 \mathrm{~kg}$ higher than the hot carcass weight of young infected lambs given low energy diet which was $124 \%$ more. Cold carcass weights followed the same pattern. Although carcass shrinkage values were not significantly different between the studied groups but they were always higher in each infected group compared to its counterpart. Dressing percentages of both hot and cold carcasses on slaughter weight base of old lambs treated for internal parasites and given high energy diet were the highest of all other groups under study. Most of treated groups had slightly higher dressing percentages than infected groups. Dressing percentage of hot carcass on empty body weight base, of old lambs treated for internal parasites and given high energy diet was $56.85 \mathrm{~kg}$ which was $12.72 \mathrm{~kg}$ higher than that of young lamb group left naturally infected and given low energy diet.

Table 5 and 6 show the interactions for dressing percentage in which the two factors dietary energy level $\times$ health status significantly affected dressing percentage when calculated on cold body weight base while age had no significant effect.

Table 5: Effect of age, health status and dietary level and their interactions on Dress \%

\begin{tabular}{|c|c|c|c|c|c|c|c|c|c|c|c|}
\hline Trait & \multicolumn{2}{|c|}{ Age } & \multicolumn{2}{|c|}{ Health status } & \multicolumn{2}{|c|}{ Dietary energy } & Age $\times$ Health & Age $\times$ Energy & Health $\times$ Energy & $\begin{array}{c}\text { AgexHealth } \\
\text { xEnergy }\end{array}$ & Overall \\
\hline LS & \multicolumn{2}{|c|}{$* *$} & \multicolumn{2}{|c|}{$*$} & \multicolumn{2}{|c|}{$* *$} & NS & NS & $*$ & NS & \multirow{3}{*}{$\begin{array}{l}51.57 \\
\mathbf{\pm 0 . 7 2}\end{array}$} \\
\hline \multirow{2}{*}{$\begin{array}{c}\text { Dress. } \\
\%\end{array}$} & Old & Young & Treated & Infected & High & Low & - & - & - & - & \\
\hline & 53.35 & 49.79 & 53.11 & 50.03 & 54.42 & 48.72 & - & - & - & - & \\
\hline
\end{tabular}

LS: Level of significance *: $(P \leq 0.05) * *:(P \leq 0.01)$ NS: Non significant Dress.\%: Dressing percentage C/E: Cold carcass weight based on empty body weight.

Table 6: Interactions of dietary level and health status on dressing percentage

\begin{tabular}{|c|c|c|c|}
\hline Health status & Energy & \multirow{2}{*}{ LS } & Dressing \% C/E \\
\hline Treated & High & \multirow{2}{*}{$*$} & 54.37 \\
\hline & Low & & 51.84 \\
\hline Infected & High & \multirow{2}{*}{$*$} & 54.47 \\
\hline & Low & & 45.60 \\
\hline
\end{tabular}

C/E: Cold carcass on bases of empty body weight (E). LS: Level of Significance

\section{Carcass yield and characteristics}

\section{Wholesale cuts yield}

Table 7 showed no significant difference in data related to wholesale cuts yield for all lamb groups of different ages, dietary energy levels and treated for internal parasites or left naturally infected. Values were taken as percentages of carcass weight. Neck cuts of infected lamb groups were slightly higher than treated groups. Average Single short forequarter percent of old treated group which was given high energy diet was $34.30 \%$ while the least one performed by the group of young lambs given low energy diet and left naturally infected which was $29.76 \%$. Leg and chump was higher but not significantly so, for the treated group except for young lambs treated for internal parasites and given high energy diet (33.38\%) which performed lesser value than their counterpart infected group (35.05\%). Loin cut of the old lamb group which was given high energy diet and treated for internal parasites was only $8.62 \%$. Best end of neck and breast and Tail cuts showed no marked differences between treatments.

\section{Loin composition}

As given in Table 8 no significant differences were found in data related to Loin composition (muscle, bone, fat, trim and fat plus trim) in terms of weight or percentage of the cut for all treatments. Only muscle percentage data showed significant differences between treatments. Old lambs given high energy diet and treated for internal parasites had the best muscle percentage $51.22 \%$ which was $5.35 \%$ more than their counterpart infected group and $9.66 \%$ more than old treated lambs given low energy diet. The best muscle bone ratio was that of young treated lambs 


\begin{tabular}{|c|c|c|c|c|c|c|c|c|c|c|}
\hline \multicolumn{5}{|c|}{ old } & \multicolumn{4}{|c|}{ Young } & \multirow[b]{3}{*}{ SE } & \multirow[b]{3}{*}{ P-value } \\
\hline & \multicolumn{2}{|c|}{ High energy } & \multicolumn{2}{|c|}{ Low energy } & \multicolumn{2}{|c|}{ High energy } & \multicolumn{2}{|c|}{ Low energy } & & \\
\hline Trait $\%^{*}$ & Treated & Infected & Treated & Infected & Treated & Infected & Treated & Infected & & \\
\hline Neck & 8.62 & 8.56 & 9.09 & 9.45 & 8.89 & 8.89 & 8.55 & 8.48 & 1.92 & NS \\
\hline $\begin{array}{l}\text { Single Short } \\
\text { fore Quarter }\end{array}$ & 34.30 & 31.23 & 30.63 & 32.76 & 30.46 & 31.52 & 31.56 & 29.76 & 5.58 & NS \\
\hline Leg \&Chump & 36.23 & 33.01 & 33.72 & 33.36 & 33.38 & 35.05 & 32.95 & 30.77 & 6.52 & NS \\
\hline Loin & 8.62 & 8.69 & 11.12 & 11.27 & 11.22 & 12.82 & 10.64 & 8.97 & 2.58 & NS \\
\hline $\begin{array}{c}\text { Best End of } \\
\text { Neck }\end{array}$ & 5.99 & 5.30 & 6.88 & 6.62 & 6.77 & 6.98 & 5.81 & 6.83 & 1.23 & NS \\
\hline Breast & 3.52 & 3.31 & 4.92 & 5.30 & 5.59 & 5.86 & 3.98 & 3.60 & 1.15 & NS \\
\hline Tail & 5.27 & 5.18 & 2.70 & 2.63 & 4.20 & 3.75 & 2.55 & 2.43 & 1.51 & NS \\
\hline
\end{tabular}

\begin{tabular}{|c|c|c|c|c|c|c|c|c|c|c|}
\hline \multicolumn{3}{|c|}{ old } & \multicolumn{5}{|c|}{ Young } & & \multirow[b]{3}{*}{ SE } & \multirow[b]{3}{*}{ P- Level } \\
\hline & \multicolumn{2}{|c|}{ High energy } & \multicolumn{2}{|c|}{ Low energy } & \multicolumn{2}{|c|}{ High energy } & \multicolumn{2}{|c|}{ Low energy } & & \\
\hline Parameter & Treated & Infected & Treated & Infected & Treated & Infected & Treated & Infected & & \\
\hline Loin (kg) & 0.82 & 0.72 & 0.77 & 0.68 & 0.84 & 0.71 & 0.74 & 0.71 & 0.15 & NS \\
\hline Muscle & 0.42 & 0.33 & 0.32 & 0.32 & 0.41 & 0.31 & 0.36 & 0.30 & 0.07 & NS \\
\hline Bone & 0.14 & 0.13 & 0.14 & 0.11 & 0.12 & 0.12 & 0.15 & 0.13 & 0.02 & NS \\
\hline Fat & 0.21 & 0.18 & 0.13 & 0.07 & 0.20 & 0.19 & 0.10 & 0.10 & 0.08 & NS \\
\hline Trim & 0.10 & 0.08 & 0.18 & 0.18 & 0.11 & 0.09 & 0.13 & 0.18 & 0.07 & NS \\
\hline Fat + Trim & 0.31 & 0.26 & 0.31 & 0.25 & 0.31 & 0.28 & 0.29 & 0.28 & 0.13 & NS \\
\hline Muscle \% & $51.22^{\mathrm{a}}$ & $45.83^{\mathrm{ab}}$ & $47.06^{\mathrm{ab}}$ & $41.56^{\mathrm{b}}$ & $48.81^{\mathrm{a}}$ & $43.66^{\mathrm{ab}}$ & $48.65^{\mathrm{a}}$ & $42.25^{\mathrm{ab}}$ & 3.70 & 0.05 \\
\hline Bone \% & 17.07 & 18.06 & 18.18 & 16.18 & 14.29 & 16.90 & 20.27 & 18.31 & 3.57 & NS \\
\hline Fat $\%$ & 25.61 & 25.00 & 16.88 & 10.29 & 23.81 & 26.76 & 13.15 & 14.08 & 10.72 & NS \\
\hline Trim \% & 12.20 & 11.11 & 23.38 & 26.47 & 14.10 & 12.68 & 17.57 & 25.35 & 4.82 & NS \\
\hline Fat+ Trim \% & 37.81 & 36.11 & 40.26 & 36.76 & 36.90 & 39.44 & 39.19 & 39.44 & 12.69 & NS \\
\hline Muscle: Bone & 3 & 2.54 & 2.29 & 2.91 & 3.42 & 2.58 & 2.40 & 2.31 & 0.54 & NS \\
\hline Muscle: Fat & 2 & 1.83 & 2.46 & 4.57 & 2.05 & 1.63 & 3.60 & 3.00 & 3.67 & NS \\
\hline $\begin{array}{c}\text { Muscle: } \\
\text { (Fat+Trim) }\end{array}$ & 1.35 & 1.30 & 1.03 & 1.25 & 1.32 & 1.11 & 1.24 & 1.07 & 0.51 & NS \\
\hline
\end{tabular}

group which was given high energy diet (3.42) followed by that of old group treated for internal parasites and on the same energy diet (3), while the worst one was 2.31 achieved by the group of young infected lambs given low energy diet.

Economic calculation of carcasses of experimental lambs

Table 4 showed that the sales of the cold carcasses of treat- ed old group that was given high energy diet had the best sales while young infected group that was given low energy diet had the worst sales.

\section{Discussion}

The present study revealed that all lambs were found to be infected with internal and or external parasites. This agreed with (14) who stated that there was not a single sheep in Sudan not infected with parasites. 


\section{Carcass characteristics}

In the present study, slaughter weight and empty body weight of old or young Sudan desert lambs fed high or low energy diets were greater in those treated for internal parasites than in those left naturally infected. This agreed with Walkden-Brown SW, et al. who had reported similar studies in which there was an increase in slaughter weight, and empty body weight following Anthelmintic treatment in ruminants [15] (Table 4). This was in line with Cardia DF who stated that, sheep gastrointestinal tract infection caused severe reduction in daily weight [8]. According to this study, level of energy of the diet accompanied with health affected hot and cold carcass weights. Both hot and cold carcass weights of old and young lambs treated for internal parasites and given high energy diets were heavier than those left naturally infected. On the other hand, old and young lambs left naturally infected and given low energy diets had lighter carcass weights. This comes along with the finding of $[7,15]$. According to this study too, dressing percentages of the hot and cold carcasses (on slaughter or empty body weight bases) of old lambs treated for internal parasites whether given high or low energy diet were significantly $(\mathrm{P}<0.05)$ higher than for old lambs left naturally infected. This agreed with Larsson EV who proved that gastrointestinal parasitic infection affected negatively weight gain and consequently carcass weight, but they did not put age in consideration [16]. This might be due to the effect of internal parasites on carcass weight. Thus infection with gastrointestinal parasites played a great role in decreasing dressing percentage value [17]. Oppositely, young lambs treated for internal parasitism and fed high energy diet were not different in their dressing percentages for the hot and cold carcass whether calculated on slaughter or empty body weight bases, from those left naturally infected. Dietary energy level and health interactions affected dressing percentage when calculated on cold body weight base while age has no effect. Shrinkage indirectly affected carcass quality. This was because carcass shrinkage loss increased in old and young lambs left naturally infected and fed on either high or low energy diets than in those treated for internal parasites. Dressing percentage of treated lambs whether old or young and fed high energy diet was $54.37 \%$ which was higher than their counter parts fed low energy diet $51.84 \%$ (Table 6). Infected lambs, whether old or young fed high energy diet had a dressing percent of $54.47 \%$ while those given low energy diet ended up with $45.60 \%$ dressing percent. This agreed with Priolo A, et al. who observed that growing animals on high energy diets generally had higher average daily gain, dressing percentage and carcass quality than those on pasture [7]. Dressing percentage of both old and young lambs which were treated for internal parasites and fed low energy diet was $51.84 \%$, meanwhile dressing percentage of both old and young lambs fed low energy diet and left naturally infected was $45.60 \%$.

\section{Economic calculation of carcasses of experimental lambs}

The sales of the cold carcasses of treated old group that was given high energy diet had the best sales while young infected group that was given low energy diet had the worst sales. That was calculated regardless of purchase prices and other cost. It goes in line with Jones $\mathrm{R}$, et al. who stated that gastrointestinal parasites have an extremely harmful effect on the sheep industry [4]. According to Lesnoff M, et al. some very highly developed countries data related to costs and treatments are relatively easily to obtain, but estimates of benefits are not, Thus it is very hard to find carcass data to compare with [18].

\section{References}

1. FAO. Food and Agricultural Organization of the United Nations, Rome, Italy. 2012.

2. Emmanuel BW, Ayeh-Kumi PF, Attah SK. Gastrointestinal parasites in ruminants at selected abattoirs in the Greater Accra region, Ghana. University of Ghana. Ghana. 2013.

3. Blackburn HD, Paiva SR, Wildeus S, Getz W, Waldron D, Stobart R, et al. Genetic Structure and Diversity among U. S. Sheep Breeds: Identification of the Major Gene Pools. J Anim Sci. 89(8): 2336-2348.

4. Jones R, Langemeier M. A review of population data utilization in beef cattle research. J Anim Sci. 2010;88(13 suppl):E32-37. doi: 10.2527/ jas.2009-2345

5. Jason S, Cameron F, Nicole S. Internal Parasite Control in Sheep. Parasite damage to sheep. 11, Australian Sheep Industry CRC. Editor: Deborah Maxwell. The University of New England: Armidale NSW 2351, DPI\&F Queensland; 2008.

6. Greer AW. Trade-offs and benefits: implications of promoting a strong immunity to gastrointestinal parasites in sheep. Parasite. Immunol. 2008;30(2):123-132. doi: 10.1111/j.1365-3024.2008.00998.x

7. Priolo A, Micol D, Agabriel J, Prache S, Dransfield E. Effect of grass or concentrate feeding systems on lamb carcass and meat quality. Meat Sci. 2000;62(2):179-185.

8. Cardia DF, Rocha-Oliveira RA, Tsunemi MH, Amarante AF. Immune response and performance of growing Santa Ines lambs to artificial Trichostrongylus colubriformis infections. Vet Parasitol. 2011;182(24):248-258. doi: 10.1016/j.vetpar.2011.05.017

9. Domke AVM, Chrtier C, Gjerde B, Leine N, Vatn S, Osteras, 0 et al. Worm control practice against gastro-intestinal parasites in Norwegian sheep and goat flocks. Acta. Vet. Scand; 2011;53(1):29. doi: 10.1186/17510147-53-29

10. Atta El Mannan A M. Investigations on gastrointestinal parasites in sheep and goats in Sennar district (Sudan). Sudan Vet. Res. 1983;5:6973.

11. Great Britain. Ministry of Agriculture, Fisheries and Food. Manual of Veterinary Parasitological Laboratory Techniques. London, UK: Her Majesty's Stationary Office; 1986.

12. MLC 1976: Meat and Livestock Commission. Birth weights and case of calving in suckler herds. Beef Improvement Services Newsletter No. 26. Bletchley: England; 1976.

13. Shaw DJ, Vercruysse J, Claerebout E, Dorny P. Gastrointestinal nematode infections of first-grazing season calves in Western Europe: general patterns and the effect of chemoprophylaxis. Vet. Parasitol. 1998;75(2-3):115-131.

14. Gagood IM, Eisa AM. Incidence and intensity of helminth parasites of sheep in the Sudan. Part one. Parasites of the abomasum. J. vet. sci. anim. husb. 1968;9:344-354. 
15. Walkden-Brown SW, Kahn LP. Nutritional modulation of resistance and resilience to gastro-intestinal nematode infection - A review. Asian-Aust. J. Anim. Sci. 2002;15(6):912-924.

16. Larsson EV. Control of gastrointestinal parasites in first and secondseason grazing cattle in Sweden. PhD thesis. University of Agricultural Sciences: Sweden;2006
17. Kosum N, Alcicek A, Taskin T, Onenc A. Fattening performance and carcass characteristics of Saanen and Bornova male kids under an intensive management system. Czech J. Anim. Sci. 2003;48(9):379-386.

18. Lesnoff M, Lancelot R, Tillard E, Dohoo IR. A steady-state approach of benefit-cost analysis with a periodic Leslie-matrix model Presentation and application to the evaluation of a sheep-diseases preventive scheme in Kolda, Senegal. Prev.Vet.Med. 2000;46(2):113-128. 